\title{
Precis of How Propaganda Works
}

\author{
Jason STANLEY
}

Received: 20/06/2016

Final Version: 05/07/2016

BIBLID 0495-4548(2016)31:3p.287-294

DOI: $10.1387 /$ theoria. 16512

ABSTRACT: Precis by the autor of the book How Propaganda Works (Princeton University Press, 2015).

Keywords: propaganda, ideology, social philosophy, political philosophy, democracy, material equality.

RESUMEN: Sinopsis del autor del libro How Propaganda Works (Princeton University Press, 2015).

Palabras clave: propaganda, ideología, filosofía social, filosofía política, democracia, igualdad material.

The overarching goal of How Propaganda Works is to provide an argument that democracy requires material equality. My aim was to forge an argument for this view without premises about morality or justice. I do so by arguing that material inequality, like other forms of inequality, has pernicious epistemic effects. Inequality results in anti-democratic flawed ideologies, such as the ideology of meritocracy, and the ideology underlying the division of labor, the subjects of the last two chapters. Propaganda plays crucial roles both in preventing us from recognizing these epistemic harms, in the form of demagoguery, and in repairing them, in the form of civic rhetoric.

The first half of the book is about propaganda. Chapter 2 advances a novel analysis of propaganda, as well as a novel explanation of its effectiveness. I split propaganda into two varieties. The first more familiar kind, which I call "supporting propaganda", employs a valued political ideal to elicit emotion devoid of reason (such as ungrounded fear, or ungrounded pride) in the service of realizing that ideal. It is another species of propaganda that is however the focus of the book, which I call undermining propaganda. Undermining propaganda is an argument that employs an ideal in the service of a goal that tends to undermine that ideal. Undermining propaganda is demagoguery when there is a flawed ideol$o g y$ in place that distorts a valuable political ideal in such a way that prevents recognition of the fact that the goal undermines the realization of the valued ideal.

Here are some basic examples that exemplify how flawed ideologies make undermining propaganda effective. Both involve the ideal of freedom, and the flawed ideology of anti-Black racism. Southerners in the United States during secession and the Civil War 
appealed to the ideal of freedom to defend their secession. A flawed racist ideology was required to mask the contradictions inherent in appealing to freedom in order to defend a social order based on the enslavement of so many. On a similar note, Frederick Douglass's 1892 speech, "The Meaning of Fourth of July for the Negro" calls attention to the way racist ideology masked the paradox of celebrating freedom on the Fourth of July under conditions of widespread enslavement.

One might wonder, however, given my explanation of why propaganda is effective, whether propaganda is at all important. If the presence of flawed ideology explains the effectiveness of propaganda, doesn't the fault lie just in the flawed ideology? This response neglects the crucially important role propaganda plays in masking flawed ideologies. In each society, there are ideals that are sacred. It is difficult to argue for policies that explicitly violate the sacred ideal. A violation of a sacred ideal must therefore often be packaged in the language of that ideal. The flawed ideology is what prevents you from recognizing that the policy proposal being advanced is in fact a violation of the very ideal that it is presented as furthering. One example is policies that restrict certain religious practices in the name of protecting liberal freedoms, such as gay rights. In the propaganda of climate change, we find oil companies and large agribusiness setting up their own "science" institutes, presenting anti-science policies under the guise of science. The "Discovery Institute" in the United States defends intelligent design against evolution, under the guise of scientific inquiry. In each case, the propagandistic guise is important to mask the flawed ideology. Undermining propaganda is the central concept of How Propaganda Works, because undermining propaganda is how we conceal from ourselves the immense gaps between liberal democratic ideals and illiberal reality.

When we think of political propaganda, we think for example (in the United States at least) of the strategy of using certain vocabulary, sometimes called "dog whistles", e.g. "welfare", and "inner city", which in the United States trigger negative racial messages, to signal adherence to problematic yet popular anti-democratic ideologies. We also think of the propaganda that accompanies social movements, emphasizing the solidarity between citizens otherwise divided by prejudice, as in the Civil Rights Movement. How do these characteristic examples of propaganda fit into my analysis of undermining propaganda?

I argue that these are cases in which the all important liberal democratic ideal of reasonableness is central. In a liberal democracy, we are supposed to consider every citizen's perspective in arguing for policy. Chapter 3 is a lengthy discussion of the notion of reasonableness, which is meant to undergird the discussion of civic rhetoric, as well as the subsequent discussion of code words in Chapter 4. As I there explain, the basis of reasonableness is empathy. Chapter 3 contains my discussion of civic rhetoric. The goal of civic rhetoric is to undermine flawed ideologies that diminish empathy. The goal of demagoguery, by contrast, is to erode empathy. Chapter 4 is a detailed description of the mechanism underlying one species of demagoguery, which exploits reasonableness against itself. For example, discussing economic policy by using words like "welfare" seems like classic reasonable political discourse. But via the mechanisms I describe in Chapter 4, such terms can be associated with unreasonable beliefs, such as that Black Americans are lazy.

In W.E.B Du Bois's classic 1926 paper, "Criteria of Negro Art", he formulates a strategy for those without power to make their perspectives visible to a dominant majority. $\mathrm{Du}$ Bois argues that the only Black artists white Americans want to see are those who fit cer- 
tain subordinating racial stereotypes; they "want Uncle Toms, Topsies, good "darkies" and clowns." His strategy is to employ art that uses the subordinating racial norms as a mask, ultimately to undermine them by revealing a Black humanity inconsistent with these subordinating and dehumanizing stereotypes. Alain Locke names this strategy, the use of "art as propaganda". Art is Du Bois's suggested tool for expanding empathy and realizing American democracy by making public spaces more reasonable, to make public discourse about policy inclusive of all perspectives.

Du Bois's paper was written during the flourishing of the Harlem Renaissance. James Weldon Johnson, the head of the National Association for the Advancement of Colored People (NAACP) in the 1920s, and a central member of the Harlem Renaissance movement, shared Du Bois's political vision of art as a vehicle for liberation. In turn, Du Bois regarded the NAACP as an ideal vehicle to plan such propaganda "And it is right here that the National Association for the Advancement of Colored People comes upon the field, comes with its great call to a new battle, a new fight and new things to fight before the old things are wholly won; and to say that the beauty of truth and freedom which shall some day be our heritage and the heritage of all civilized men is not in our hands yet and that we ourselves must not fail to realize."

The popular 1921 Broadway play Shuffle Along is a classic example of the use of Du Bois's strategy. The writers met at an NAACP benefit, and the play was written by Black authors, produced by Black citizens, and starred Black performers. Marketed, as is evident from its title, to appeal to whites with a simplistic stereotyped vision of Black existence, it used novel forms of jazz to call attention to the vastly greater complexity and humanity of Black American life. It is civic rhetoric in the form of undermining propaganda.

Civic rhetoric also of course takes the form of supporting propaganda. Here, it to realize the ideals of liberty and equality, by appealing to audience's emotional connection to these ideals. Here, I use the work of Melvin Rogers to illuminate the ways in which Du Bois and others employed civic rhetoric in this way, as a direct attempt to increase the realization of democratic ideals.

Civic rhetoric attempts to expand empathy and realize the ideal of reasonableness. In contrast, demagogic propaganda in a liberal democracy masks violations of reasonableness, by making certain perspectives invisible. Chapter 4 is an investigation of one way in which demagogic propaganda can occur, unnoticed, in a liberal democracy.

Though Chapter 4 is extensive, its scope is limited. In it, I work out in detail how one class of political propaganda fits into my framework. Chapter 4 is not in any sense meant to be a general account of undermining propaganda. It just so happens that the tools of linguistics allow us to give a detailed account of one characteristic mechanism by which reasonableness is used to undermine reasonableness (often called "code words"). In this chapter, I show how repeated association between words and messages can create a second level of communicated content, which can be made precise in with distinctions drawn in recent semantics and pragmatics. On one level of content, the "official" level, a discourse can seem reasonable. Yet because of the additional, second level of communicated content, the communicative act can be unreasonable.

In Chapter 4, I give a detailed account of a mechanism of propaganda. But most of the examples of effective undermining propaganda I discuss in the book do not exploit the semantic and pragmatic apparatus discussed in Chapter 4. For example, none of the seven ex- 
amples of undermining propaganda discussed at the end of Chapter 2 require invocation of the semantic and pragmatic apparatus of Chapter 4. The topic of "code words" allows for systematic detailed investigation in ways that other examples either do not allow, or do not require.

The rest of How Propaganda Works is about the topic of ideology. Kristie Dotson (2014) characterizes epistemic oppression as:
...persistent epistemic exclusion that hinders one's contribution to knowledge production. Epis- temic exclusion, here, will be understood as an unwarranted infringement on the epistemic agency of knowers. Epistemic agency, in this analysis, refers to the ability to utilize persuasively shared epistemic resources within a given community of knowers in order to participate in knowledge production and, if required, the revision of those same resources. ${ }^{1}$

How Propaganda Works situates the topic of epistemic oppression in the long history of democratic political philosophy. I argue that inequality results in characteristic kinds of flawed ideologies, and possession of these flawed ideologies result in various kinds of epistemic oppression. The book situates epistemic oppression in the context of democratic political philosophy in the structure familiar from leading political philosophers of previous eras, such as W.E.B. Du Bois and John Dewey, where philosophy of education was at its center. A democracy requires a public culture with social conditions that enable democracy. The topic of how to bring out these social conditions, for example by a civic education, received much more attention in previous eras.

Chapter 5 is a general overview of my favored account of flawed ideology. Chapters 6 and 7 are devoted to two flawed ideologies that emerge in conditions of inequality, in the process of justifying the inequalities. The subject matter of Chapter 6 is the ideology of meritocracy. The subject matter of Chapter 7 is the ideology of a natural distinction between practical and theoretical pursuits. I place these ideologies in their lengthy historical context in democratic political philosophy, and argue that they are almost invariably democratically problematic. These ideologies are frequent sources of ignorance about important facets of social and political reality. I also explain the ideological function of these epistemically problematic features, that is, their role in justifying hierarchical social orders.

In Chapter 5, I use Dan Kahan's account of identity protective cognition to give an account of ideology that is normatively neutral, as in Sally Haslanger's work. ${ }^{2}$ I then characterize the notion of a flawed ideology. Since I intend my arguments not to rely on moral or political premises, the notion of flaw in question is epistemic. A flawed ideology of a domain is one that prevents the acquisition of important knowledge about that domain. I explain how the epistemically problematic features of flawed ideologies function ideologically, in preventing the acquisition of knowledge, by implementing various forms of epistemic injustice and oppression.

A central example in the book, and developed in chapter 5, is the flawed ideology of technicism. Technicism restricts reasons to those that can be given in a specific form, those

1 Kristie Dotson (2014), “Conceptualizing Epistemic Oppression”, Social Epistemology: A Journal of Knowledge, Culture and Policy.

2 See Sally Haslanger, Resisting Reality (Oxford: Oxford University Press, 2012). 
given in the language of technical expertise. Chapter 2, the central chapter of the book, begins with Samuel Huntington's trilateral commission report on the crisis of democracy, which calls for the use of "experts" to make citizens feel like they do not have the capacity to participate democratically in institutional accountability. ${ }^{3}$ Technicism is a flawed ideology, because it seals those subject to it off from important sources of testimony about social and political reality.

Chapter 6 is about the ideology of meritocracy. The chapter is devoted to arguing that in conditions of inequality, a robust ideology will emerge among those who are at the top of the hierarchy that their status is deserved. I use social psychology to help explain why the ideology emerges. I use work in analytic epistemology to explain why the ideology is robust even in the face of clear counter-evidence. Here, I draw on work of my own and others on the "interest-relativity" of knowledge, which entails that having more at stake raises epistemic barriers that suggests the existence of genuine epistemic barriers in policy deliberation for those worst off. Such barriers, as standpoint epistemologists have long argued, are countered by the epistemic privilege of oppressed social position. But flawed ideology prevents elites from recognizing epistemic privilege of this kind. I conclude by arguing that elites who benefit from inegalitarian social structures suffer more extreme epistemic harm than those oppressed by them. Elites have moral interests at stake. These moral interests raise epistemic barriers to elite's knowledge even more pressing than the ones facing the disadvantaged. The ideology robs the elite of agency in decision making. Material inequality poisons the epistemic space required for democratically legitimate policy formation, by a general and pervasive occlusion of social and political reality.

Even if one retains knowledge, being treated as if one lacks knowledge is an epistemic harm. Rae Langton defines silencing as "[stopping] speech from counting as an action." What she here means is that although denials are made, they are counted as having been made. She unquestionably takes this to be a kind of epistemic oppression or injustice. Similarly, if one knows, but is treated by dominant groups as not knowing, that is epistemic oppression. It is true that I have an argument that connects power to knowledge. Knowledge is sufficient for action, and sometimes power prevents action. But nothing in my overall argument in the book depends on taking this extra step.

Though I do not need to be for the purposes of my book, I am unfashionably drawn to the view that dominant ideology must be taken seriously as a potential causal factor on mass opinion. Never very popular, the notion of false consciousness has fallen upon particularly hard times. The doctrine of false consciousness prima facie presupposes something like Rousseau's General Will. The consciousness is false because it is not true to the real desires of the agents who have it. But who determines the real desires?5 Or perhaps the consciousness is false because it justifies a picture of the world that does not correspond to reality. But who is the arbiter of reality? These problems and other difficulties for false

3 Patricia Hill Collins describes the ideology of technicism as the conceptual scheme of "Eurocentric Knowledge Validation Processes".

4 Rae Langton, "Speech Acts and Unspeakable Acts", Philosophy and Public Affairs (1993): 293-330.

5 In "Die Selbstbehauptung der deutschen Universität", his Rektoratsrede, Martin Heidegger decries the "Academic freedom" of German Universities, as mere negative freedom. True freedom, he argues is in "den geistigen Auftrag des deutschen Volkes". 
consciousness theses have been a persisting theme of democratic political philosophy from Benjamin Constant, through Isaiah Berlin, to today. ${ }^{6}$

In addition to problems of misuse, there are also worries about its faithfulness to reality and objectification of oppressed groups. Michael Rosen (1996, pp. 181-3) ridicules "the interests model" of ideological false consciousness, that treats "those who live under the domination of the ruling class as passive victims, taking their lives from those who control 'the means of production' like obedient chicks, with no critical reflection on their part are true or in their own rational interests." James C. Scott argues that it is quite evident that the dominated class is not imaginatively restricted about alternative and better world possibilities, they are not deprived of epistemic resources in the way that dominant ideology theory predicts. ${ }^{8}$ There are also many distinct reasons to worry about coherence. For example, Serene Khader has brought out powerfully certain incoherence worries about the false consciousness thesis of adaptive preferences. ${ }^{9}$

Does this mean we cannot make sense of the thought that an oppressed group accepts an ideology that runs counter to their interests? The case of the ideology of meritocracy is a promising example of dominant ideology theory at work. Surely there are some people who grew up in structural conditions that disadvantaged them in a way that clearly is inconsistent with a meritocratic society, who nevertheless believe that society is meritocratic. Two other examples I provide are British Imperialism in East Africa (pp. 235-6), and the 2003 Iraq War.

Each of these examples of the imposition of dominant group ideology can be contested. ${ }^{10}$ But even the harshest critics of false consciousness admit that "public action will provide a constant stream of evidence that appears to support an interpretation of ideological hegemony." ${ }^{11}$ I agree with critics that appearances are often deceptive. But I also think that

${ }^{6}$ Benjamin Constant (1819), "The Liberty of the Ancients compared with that of the Moderns", speech given at the Athénée Royal, decries the mistaking of "the authority of the social body for liberty" (in Constant: Political Writing, edited by Biancamaria Fontana, (Cambridge, Cambridge University Press, 1988: 307-328, at 318), and of course famously in the 20th century the point that positive freedom is too frequently propagandistically exploited is made by Isaiah Berlin, in "Two Concepts of Liberty", in The Proper Study of Mankind (1997) (New York: Farrar, Straus, and Giroux).

7 The interests model is just one of five different models of ideology that Rosen (1996, chapter 6) sources in Marx's writings. All of them are false consciousness theses, but they explain the false consciousness in different and often incompatible ways. The version of ideology he takes most serious treats it as a form of functional explanation ("the correspondence model").

8 See James C. Scott, Domination and the Arts of Resistance (New Haven, Yale University Press, 1990), Chapter 4, "False Consciousness or Laying it on Thick?".

9 Serene Khader, chapter 2 of Adaptive Preferences and Women's Empowerment (Oxford University Press, 2011).

${ }^{10}$ Gaile Pohlhaus, Jr., in her essay in this volume, rightly critiques my book for depending on an analysis that ignores intersectionality. She also has sketched an alternative account of the Iraq War case, that does not depend upon appeal to anything like the acceptance of dominant group ideology. Perhaps the fact that so many Americans were convinced by government propaganda in 2003 can be explained by the fact that even poor Americans have intersectional identities that make them dominant over poor Iraqis. That's a brilliant avenue of explanation that did not occur to me when writing the book. I am not sure however that it is descriptively adequate; more discussion is required.

${ }^{11}$ James C. Scott (1990, p. 70). 
history shows us that there are specific times and places at which the problem of mass opinion becomes pressing to political theorists, its existence hard to deny.

One such period was the time between World War I and World War II. It is during this time that Walter Lippmann, Carl Schmitt, John Dewey, W.E.B. Du Bois, and others who have deeply affected the narrative of How Propaganda Works engaged with the problem. As Walter Lippmann and especially Carl Schmitt noted, elites manipulate mass opinion during war time. Moments of mass extermination, of the sort that occurred under Hitler and Stalin, certainly also call for reflection on mass opinion formation. And the present moment in Europe and the west, where far right nationalist politicians are garnering ever more support, may turn out to be another. John Dewey thought it was so important for citizens to reflect on the problem of the crafting of mass opinion by elites that his influence on the social studies curriculum in the United States was a final $12^{\text {th }}$ grade year on the subject. The standard textbook for $12^{\text {th }}$ grade social studies became Harold Rugg's An Introduction to Problems of American Culture, a book that calls upon students to reflect upon the reality of elite formation of mass opinion.

That said, the central moral of chapter 6 is independent of any commitment to dominant ideology theory. The Chapter is about the ideology of meritocracy. It is clear that in societies in which this ideology is robustly held, it is a problem because of its robustness and preponderance in the dominant class. If there is a social injustice that threatens meritocracy, the elite will not notice it. If the ideal of meritocracy is distant enough from reality, it will rob the elite of agency in democratic deliberation. The central moral of Chapter 6 is about the negative epistemic effects of material inequality on the elite.

Chapter 7 is about the ideology that underlies the division of labor, the separation of humans into those who labor and those who lead. The ideology I consider is the view that there is a distinction of natural capacities that underlies the division of tasks and occupations into the practical and the theoretical. There is a division between manual labor, craft, and theoretical reflection, but as Antonio Gramsci urges in the case of the concept of an intellectual, it is only social and political in nature. There is no distinction of natural capacities that underlie dividing tasks into menial, practical, and theoretical. This ideology is an attempt to give a naturalistic justification of the assignment of large groups of people to menial labor, or vocational education, while keeping liberal education just for an elite few.

Drawing on arguments I have developed in books and papers about the nature of knowledge how and skill, I argue that there is a no naturalistic basis for a division between even manual labor and intellectual reflection. Rather than justifying the ideology, the work in philosophy and cognitive neuroscience rather reflects it.

I link the work I have done on knowing how and skill to Gramsci's notion of "organic intellectuals", arguing that it vindicates Gramsci's view that intelligent decision making and knowledge are present even in the most menial industrial tasks. If the account of knowledge how I defend is right, even the most menial manual practices, such as factory work, exemplifies agency, free intelligent choice. The consequences of this are far-reaching. It is not that some people in society are gifted in theoretical reflection, others in craft, while the remainder must be consigned to ditch digging and menial industrial work. Each skill is a combination of elements that are operative in other domains as well. These conclusions undermine the sorting of humans into labor pools, as well as its putative educational basis, the distinction between industrial or vocational education, on the one hand, and liberal education, on the other.

In the first twenty years of the $20^{\text {th }}$ century in the United States, there was another kind of systematic attempt to give a scientific basis to the division of labor. It was called the "so- 
cial efficiency" movement. On the face of it, the movement was a search for a social scientific basis to the separation of students into those who would receive vocational education, from those who would receive a liberal education. Advocates of social efficiency used quantitative research to justify grouping individuals into life outcomes from an early stage. I argue that the social efficiency movement was in fact quite explicitly grounded on a desire to impose social control. Rather than serving as an independent scientific basis for sorting society into hierarchical levels, it was explicitly an attempt to justify hierarchical divisions of worth between citizens, with a pseudo-scientific overlay in place for propaganda purposes.

Chapter 7 , like the chapters before it, is structured by the analysis of numerous important examples of undermining propaganda. One example is the debate during the formation of the United States public school curriculum in the early part of the $20^{\text {th }}$ century about whether to teach History or Social Studies in public schools. This debate is sometimes called in the literature, "The Social Studies Wars" (also the title of a book on the topic). Should one teach history, with all its particularities? Or should one instead devote that time to constructing a narrative that departs from history, but has a useful societal function? It was decided to teach Social Studies instead of history, featuring a uniform narrative of American identity that would be useful in, for example, assimilating new waves of immigrants.

John Dewey argued for the need for a class in civic education, to engage students in what he regarded as the fundamental task of a democratic citizen, the mutual construction of a shared civic identity. Thinking social studies would be this class, Dewey weighed in on the side of social studies. But Dewey did not recognize that what he regarded as a bottom up exercise in the construction of an American identity, the social studies curriculum, was largely instead a top down effort to impose such an identity on students for the purposes of social control. ${ }^{12}$ We see, in the history of the United States public school system, a paradigm example of the propagandistic misuse of the ideals of positive freedom.

In the discussion of the basis for the $20^{\text {th }}$ century US public school system, we also see the characteristic kind of undermining propaganda that occurs with social science research, what Alasdair MacIntyre has called "manipulative expertise". The ideals of science were employed propagandistically to justify pre-existing unjust hierarchies. For example, advocates of social efficiency argued that liberal education was wasted on women, as the statistics showed most women who acquired a higher education nevertheless did not enter the workforce. But that is no justification at all for the frighteningly patriarchal society of the time, where female educational achievements did not afford them anywhere near the same opportunities as similar achievements by men.

Jason Stanley is the Jacob Urowsky Professor of Philosophy at Yale University. Before coming to Yale in 2013, he was Distinguished Professor in the Department of Philosophy at Rutgers University. He has also been a Professor at the University of Michigan and Cornell University. His PhD was earned in 1995 at the Department of Linguistics and Philosophy at MIT. Professor Stanley has published four books, two in epistemology, one in philosophy of language and semantics, and a recent one in social and political philosophy, How Propaganda Works, which was published by Princeton University Press in May, 2015. It was the winner of the 2016 PROSE award for the subject area of philosophy.

Address: P.O. Box 208306. Yale University. New Haven, CT 06520, USA. E-mail: Jason.stanley@yale. edu.

12 Until the 12 grade at least, which, as noted above, was handed to Dewey. 